\title{
Metabolic syndrome biomarkers and early breast cancer in Saudi women: evidence for the presence of a systemic stress response and/or a pre-existing metabolic syndrome-related neoplasia risk?
}

Majed S Alokail ${ }^{1,2}$, Nasser Al-Daghri ${ }^{1,2,7^{*}}$, Amal Abdulkareem ${ }^{3}$, Hossam M Draz $^{1,4}$, Sobhy M Yakout ${ }^{1}$, Abdullah M Alnaami ${ }^{1}$, Shaun Sabico ${ }^{1}$, Amal M Alenad ${ }^{5}$ and George P Chrousos, ${ }^{1,6}$

\begin{abstract}
Background: Obesity has been linked to many adverse health consequences, including breast cancer. This study aims to determine adipocytokine and other biological changes in recently diagnosed breast cancer patients before therapy is started.

Methods: A total of 109 female Saudi subjects [56 newly diagnosed, treatment-naive, histologically-confirmed breast cancer cases and 53 age- and BMI-matched controls] were enrolled in this study. Anthropometric data were collected. Serum insulin, adipocytokines and plasminogen activator inhibitor-1 (PAl-1) concentrations were measured using a customized multiplex Luminex assay. Hypersensitive C-Reactive Protein (CRP), tumor necrosis factor-alpha (TNF-a), and angiotensin II (ANG II) were measured using ELISA.

Results: A few days in the diagnosis, breast cancer subjects had significantly higher systolic blood pressure $(p=0.03)$, glucose $(p=0.01)$, triglycerides $(p=0.001)$, leptin $(p=0.044)$, resistin $(p=0.04)$, ANG $\|(p=0.02)$, TNF-a $(p=0.045)$, and CRP $(p=0.04)$ than the controls. On the other hand, HDL $(p=0.01)$ and adiponectin $(p=0.02)$ were significantly lower in cancer subjects than controls. A significant association was found between elevated triglycerides (TG) and breast cancer [OR (95\% Cl), $6.1(1.8,15.6), p=0.004$ ], as well as elevated ANG II [OR $(95 \% \mathrm{CI}), 5.2(1.2,14.3), p=0.03]$. On the other hand, aPAI and HDL correlated negatively with breast cancer [OR $(95 \% \mathrm{Cl}), 0.076(0.01,0.34), p=0.001 ; 0.30(0.09,0.95), p 0.04$, respectively].

Conclusion: Circulating ANGII and triglycerides were positively associated with early breast cancer. In contrast, $\mathrm{HDL}$-cholesterol correlated negatively with ANG II and aPAI in these patients. This suggests that patients with recently diagnosed breast cancer have biochemical changes consistent with an activated stress response and/or that patients with metabolic syndrome manifestations have a higher risk of developing this disease.
\end{abstract}

Keywords: Breast cancer, Saudi women, Adiponectin, Leptin, HDL

\footnotetext{
* Correspondence: aldaghri2011@gmail.com

'Biomarkers Research Program, Biochemistry Department, College of Science,

King Saud University, Riyadh 11451, Kingdom of Saudi Arabia (KSA)

${ }^{2}$ Center of Excellence in Biotechnology, King Saud University, Riyadh 11451,

KSA

Full list of author information is available at the end of the article
} 


\section{Background}

Overweight and obesity, a global phenomenon, affects more than 1 billion adults, with 300 million being clinically obese [1]. Obesity has a major impact on the risk and prognosis of some of the more common forms of cancer, but also provides us with one of the few preventive interventions capable of making a significant impact on the cancer problem [2]. Weight increase and obesity in menopausal females have been identified as the most important prognostic risk factors for breast cancer in postmenopausal women [3]. Several studies have reported that at diagnosis of breast cancer, obese women exhibit an increase in lymph-node involvement and a higher propensity to develop distant metastases [4,5].

Breast cancer is the most commonly occurring female cancer in the industrialized world. Although early diagnosis has contributed to therapeutic success, breast cancer remains a major female health issue and its incidence is increasing in developing countries [3]. Genetic predisposition and environmental factors, such as a high fat diet and alcohol consumption, accompanied with a sedentary life style had been reported to cause an increase in breast cancer risk $[3,6]$.

Metabolic Syndrome, including obesity and T2DM, are positively associated with an increased breast cancer risk $[7,8]$. These conditions are associated with changes in several hormonal systems, including insulin, estrogen, cytokines and growth factors [3]. Recent studies have linked breast cancer with insulin resistance [9-11]; metabolic syndrome (MetS) [12,13], and altered adipokine levels [14].

Alteration in adipocytokine production in obese subjects has been reported in several studies. Studies have shown that increased leptin and decreased adiponectin levels promote carcinogenesis of the breast [15-18]. It was also shown that adiponectin has prognostic significance in breast cancer recurrence [10]. In addition, obesity is being increasingly recognized as a form of systemic subclinical inflammation and, accordingly, an increased adipose tissue infiltration by immune cells producing inflammatory substances, including C-reactive protein (CRP) and tumor necrosis factor-alpha (TNF- $\alpha$ ), which have a positive impact on the breast cancer development [19-21]. CRP is positively and negatively correlated with leptin and adiponectin levels, respectively [22,23]. Independent effect of CRP and alterations in the levels of both leptin and adiponectin were altogether accompanied by an increase in breast cancer risk incidence [24].

This aim of this study was to further examine adipocytokines and other metabolic and immune biomarkers of metabolic syndrome linked with obesity in patients with early breast cancer prior to therapy initiation.

\section{Methods}

A case-control study was conducted by the Biomarkers Research Program (BRP), College of Science, King Saud University, Riyadh, Kingdom of Saudi Arabia (KSA). Ethical approval for the study was granted by the Ethics Committee of King Khalid Hospital, King Saud University, Riyadh, Kingdom of Saudi Arabia (KSA). A total of 109 female Saudi subjects, consisting of 56 newly diagnosed, histologically-confirmed breast cancer with no prior breast cancer treatment and 53 age- and BMI-matched controls were enrolled in this study. All of the control subjects were confirmed free from benign or malignant breast diseases and women with a personal or family history of any tumor was excluded. All subjects were free from acute medical conditions, including infections, at the time of inclusion. Control samples were matched according to the age and BMI of cases and were taken from an existing database from the Biomarkers Research Program. Written informed consent for the utilization of serum samples and personal information through a questionnaire for the purpose of research was obtained from all subjects.

\section{Anthropometrics}

Anthropometric data were collected by a designated research nurse and physician: Height (to the nearest $0.5 \mathrm{~cm}$ ), weight (to the nearest $0.1 \mathrm{~kg}$ ), waist and hip circumference (measured using a standardized measuring tape in $\mathrm{cm}$ ) in addition to systolic and diastolic blood pressure measurements. Body mass index (BMI) was calculated as $\mathrm{kg} / \mathrm{m}^{2}$. WHR was also calculated as waist divided by hip circumference. Fasting blood samples from cases were extracted after diagnosis and prior to breast cancer therapy initiation. Blood was transferred immediately to a non-heparinized tube for centrifugation. Serum was then transferred to a pre-labeled plain tube, stored in ice, and delivered to the Biomarker Research Center in King Saud University on the same day.

\section{Metabolic measurements}

Fasting serum samples were stored in a $-20^{\circ} \mathrm{C}$ freezer prior to analysis. Serum glucose, triglycerides, total and HDL-cholesterol levels were measured by chemistry auto-analyzer (Konelab, Espoo, Finland) and concentrations of LDL-cholesterol were calculated using Friedwald's formula. Determination of serum insulin, leptin, adiponectin, resistin, and aPAI-1 was done using customized multiplex assay kits that utilize the Luminex ${ }^{\circledR}$ $\mathrm{xMAP}^{\circledR}$ Technology platform (Luminex Corporation, Texas, USA).

For parameters measured using the multiplex assay, the intra-assay variation was $1.4-7.9 \%$ and inter-assay variation of $<21 \%$. Minimum detectable concentrations (MDC) were as follows: insulin $50.9 \mathrm{pg} / \mathrm{ml}$; leptin 85.4 
$\mathrm{pg} / \mathrm{ml}$; adiponectin $145.4 \mathrm{pg} / \mathrm{ml}$; resistin $6.7 \mathrm{pg} / \mathrm{ml}$; and PAI-1 $1.3 \mathrm{pg} / \mathrm{ml}$. The rest of the parameters were quantified using individual enzyme-linked immunosorbent assay kits (ELISA): CRP (Immunodiagnoztik AG, Germany) with an intra-assay variability of $5.5-6.0 \%$ and inter-assay variation of 11.6-13.8\%; TNF- $\alpha$ (Biosource, Belgium); ANG-II ( $\mathrm{R}$ and $\mathrm{D}$ Systems, MN).

\section{Statistical analysis}

Data analysis was carried out using the Statistical Package for the Social Sciences (SPSS for Windows, version 16.0). Power calculation was done ascertaining differences in mean CRP levels between cases and controls. A total sample size of 88 has $80 \%$ power to detect a significance at $\alpha=0.03$. Data are expressed as mean \pm standard deviation, while medians (inter-quartile range) were shown for non-normal continuous variables. Independent student $\mathrm{t}$-test was used to compare group differences for normal parameters. For non-normal parameters, Mann-Whitney U-test was utilized. Multinomial logistic regression analysis was done using the presence of breast cancer as dependent variable and parameters of interest as independent variables adjusted for menopause and age of menarche. Partial correlation analysis was used to determine associations between variables of interest. Significance was set at $p<0.05$. All statistical analyses were conducted using SPSS version 16.5 (Chicago, IL).

\section{Results}

Table 1 highlights the general characteristics of our female subjects. Data revealed that breast cancer subjects had significantly higher systolic blood pressure $(p=$ $0.03)$, glucose $(p=0.01)$, triglycerides $(p=0.001)$, leptin $(p=0.044)$, resistin $(p=0.04)$, Ang II $(p=0.02)$, TNF- $\alpha$ $(p=0.045)$, and CRP $(p=0.04)$ than controls. On the other hand, HDL $(p=0.01)$ and adiponectin $(p=0.02)$ were significantly lower in breast cancer subjects than controls. The rest of the comparisons were noncontributory.

Table 2 shows odds ratios for breast cancer in relation to glucose, HDL, triglycerides, CRP, ANG II, adiponectin, leptin, TNF- $\alpha$, aPAI, and resistin levels. A significant association was found between elevated levels of triglycerides and risk of breast cancer [OR (95\% CI), 6.1 (1.8, 15.6), $p=0.004]$. Significant associations were also found between elevated levels of ANG II and risk of developing breast cancer in females [OR $(95 \% \mathrm{CI}), 5.3(1.2,14.3)$, $p=0.03]$. On the other hand aPAI and HDL had a protective effect with the risk of developing breast cancer [OR (95\% CI), 0.076 (0.01, 0.34), $p=0.001 ; 0.30$ (0.09, $0.95), p=0.04$, respectively].

Linear regression analyses using CRP, ANG II, adiponectin, leptin, TNF- $\alpha$, aPAI, and resistin as dependent
Table 1 General characteristics of subjects

\begin{tabular}{|c|c|c|c|}
\hline & Control & Breast cancer & $P$ value \\
\hline $\mathrm{N}$ & 53 & 56 & \\
\hline Age (years) & $43.1 \pm 7.5$ & $46.4 \pm 11.3$ & 0.10 \\
\hline Age at Menarche (years) & $13.1 \pm 1.0$ & $12.9 \pm 1.6$ & 0.48 \\
\hline Age at $1^{\text {st }}$ Pregnancy (years) & $21.0 \pm 3.8$ & $19.6 \pm 4.3$ & 0.19 \\
\hline Menopause (\%) & $9(17)$ & $22(40)$ & 0.01 \\
\hline Body Mass Index $\left(\mathrm{kg} / \mathrm{m}^{2}\right)$ & $31.0 \pm 5.4$ & $31.4 \pm 7.7$ & 0.81 \\
\hline Systolic BP (mmHg) & $112.3 \pm 11.98$ & $118.6 \pm 15.5$ & 0.03 \\
\hline Diastolic BP (mmHg) & $73.3 \pm 7.0$ & $70.9 \pm 10.5$ & 0.22 \\
\hline $\mathrm{SAD}(\mathrm{cm})$ & $22.1 \pm 5.8$ & $20.2 \pm 8.3$ & 0.30 \\
\hline Waist circumference $(\mathrm{cm})$ & $88.8 \pm 18.8$ & $96.3 \pm 22.2$ & 0.08 \\
\hline Hip circumference (cm) & $106.5 \pm 21.4$ & $105.5 \pm 18.2$ & 0.81 \\
\hline Glucose $(\mathrm{mmol} / \mathrm{l})$ & $5.4 \pm 0.63$ & $5.9 \pm 1.2$ & 0.01 \\
\hline Triglycerides (mmol/l) & $1.3 \pm 0.22$ & $1.9 \pm 0.38$ & 0.001 \\
\hline Total Cholesterol (mmol/l) & $4.7 \pm 0.62$ & $4.9 \pm 1.0$ & 0.27 \\
\hline LDL-Cholesterol (mmol/l) & $3.6 \pm 0.76$ & $3.7 \pm 1.0$ & 0.51 \\
\hline HDL-Cholesterol (mmol/l) & $0.86 \pm 0.29$ & $0.72 \pm 0.26$ & 0.01 \\
\hline C-Reactive Protein (ug/ml) & $4.4 \pm 0.11$ & $7.5 \pm 0.21$ & 0.04 \\
\hline ANG II (ng/ml) & $0.77 \pm 0.15$ & $0.99 \pm 0.29$ & 0.02 \\
\hline Leptin (ng/ml) & $16.0 \pm 2.2$ & $25.6 \pm 1.7$ & 0.044 \\
\hline Adiponectin (ug/ml) & $19.1 \pm 1.2$ & $14.8 \pm 1.0$ & 0.02 \\
\hline TNF-a (pg/ml) & $4.6 \pm 0.57$ & $6.0 \pm 0.75$ & 0.045 \\
\hline aPAl (ng/ml) & $14.6 \pm 1.3$ & $12.2 \pm 2.8$ & 0.08 \\
\hline Resistin (ng/ml) & $15.2 \pm 1.0$ & $18.9 \pm 1.2$ & 0.04 \\
\hline $\mathrm{Ca}(\mathrm{mmol} / \mathrm{l})$ & $2.4 \pm 0.23$ & $2.3 \pm 0.58$ & 0.18 \\
\hline $\mathrm{Pi}(\mathrm{mmol} / \mathrm{l})$ & $1.2 \pm 0.18$ & $1.6 \pm 0.34$ & $<0.001$ \\
\hline
\end{tabular}

Note: Data presented as mean \pm SD; P-value significant at $<0.05$.

Table 2 Menopausal status and Age of menarche -adjusted Odds-ratio [confidence interval (Cl) $95 \%$ for Breast cancer in Relation to Glucose, HDL, Triglycerides, CRP, ANG II, Adiponectin , Leptin, TNF-a, aPAI, and Resistin levels

\begin{tabular}{lcc}
\hline & Odds ratio $(95 \% \mathrm{Cl})$ & P-Value \\
\hline Glucose $(\mathrm{mmol} / \mathrm{l})$ & $2.2(0.68,7.1)$ & 0.63 \\
Triglycerides (mmol/) & $6.1(1.8,15.6)$ & 0.004 \\
HDL-Cholesterol (mmol/l) & $0.30(0.09,0.95)$ & 0.04 \\
C-Reactive Protein (ug/ml) & $2.1(0.53,8.1)$ & 0.29 \\
ANG II (ng/ml) & $5.3(1.2,14.3)$ & 0.03 \\
Leptin (ng/ml) & $1.6(0.33,7.9)$ & 0.53 \\
Adiponectin (ug/ml) & $0.44(0.12,1.5)$ & 0.19 \\
Resistin (ng/ml) & $1.9(0.62,5.7)$ & 0.26 \\
TNF-a (pg/ml) & $1.59(0.44,5.7)$ & 0.47 \\
aPAl (ng/ml) & $0.076(0.01,0.34)$ & 0.001 \\
\hline
\end{tabular}

Note: P-value significant at $p<0.05$. 
Table 3 Correlation analysis using CRP, ANG II, Adiponectin, Leptin, TNF-a, aPAl and Resistin as dependent variables in all subjects, controls and cases

\begin{tabular}{|c|c|c|c|c|c|c|c|}
\hline & $\begin{array}{c}\text { CRP } \\
\text { All; Control; } \\
\text { Cases }\end{array}$ & $\begin{array}{c}\text { ANG II } \\
\text { All; Control; } \\
\text { Cases }\end{array}$ & $\begin{array}{c}\text { Leptin } \\
\text { All; Control; } \\
\text { Cases }\end{array}$ & $\begin{array}{l}\text { Adiponectin } \\
\text { All; Control; } \\
\text { Cases }\end{array}$ & $\begin{array}{l}\text { Resistin } \\
\text { All; Control; } \\
\text { Cases }\end{array}$ & $\begin{array}{c}\text { TNF-a } \\
\text { All; Control; } \\
\text { Cases }\end{array}$ & $\begin{array}{c}\text { aPAl } \\
\text { All; Control; } \\
\text { Cases }\end{array}$ \\
\hline \multicolumn{8}{|l|}{ Age (years) } \\
\hline BMI $\left(\mathrm{kg} / \mathrm{m}^{2}\right)$ & $0.38^{* *} ; \mathrm{NS} ; 0.52^{* *}$ & & $0.32^{* *} ; \mathrm{NS} ; 0.44^{* *}$ & & & & \\
\hline Systolic BP (mmHg) & & & & & & & NS; NS; $0.36^{*}$ \\
\hline Diastolic BP (mmHg) & & & & & & & $0.25^{*} ; \mathrm{NS} ; \mathrm{NS}$ \\
\hline \multicolumn{8}{|l|}{$\mathrm{SAD}(\mathrm{cm})$} \\
\hline Waist (cm) & $0.44^{* *} ; \mathrm{NS} ; 0.48^{* *}$ & & $0.23^{*} ; \mathrm{NS} ; \mathrm{NS}$ & $-0.35^{* *} ; \mathrm{NS} ;-0.45^{* *}$ & & & \\
\hline Hips (cm) & NS; NS; $0.35^{*}$ & & $0.25^{*} ; \mathrm{NS} ; 0.44^{*}$ & & & & \\
\hline Glucose (mmol/l) & & & & NS; NS; $-0.38^{*}$ & & & $0.28^{*} ; \mathrm{NS} ; \mathrm{NS}$ \\
\hline $\begin{array}{l}\text { Total Cholesterol } \\
(\mathrm{mmol} / \mathrm{l})\end{array}$ & & & & & & & $-0.28^{*} ; \mathrm{NS} ; \mathrm{NS}$ \\
\hline Triglycerides (mmol/l) & & & & $-0.26^{*} ; \mathrm{NS} ; \mathrm{NS}$ & & $0.26^{*} ; \mathrm{NS} ; 0.28^{*}$ & \\
\hline $\begin{array}{l}\text { HDL-Cholesterol } \\
(\mathrm{mmol} / \mathrm{l})\end{array}$ & & & & $0.23^{*} ; \mathrm{NS} ; \mathrm{NS}$ & & & \\
\hline $\begin{array}{l}\text { LDL-Cholesterol } \\
(\mathrm{mmol} / \mathrm{l})\end{array}$ & NS; $0.38^{*} ;$ NS & & & & & & $-0.29 * * ;-0.31^{*}$ \\
\hline CRP (ug/ml) & & & $0.26^{*} ; \mathrm{NS} ; 0.40^{*}$ & $-0.27^{*} ;-0.32^{*} ; \mathrm{NS}$ & $-0.26^{*} ; \mathrm{NS} ;-0.32^{*}$ & & \\
\hline ANG $\|(n g / m l)$ & & & & & & & $N S ; 0.48^{* *} ; N S$ \\
\hline Leptin (ng/ml) & $0.26^{*} ; \mathrm{NS} ; 0.41^{*}$ & & & & & $0.23^{*} ; \mathrm{NS} ; \mathrm{NS}$ & \\
\hline Adiponectin (ug/ml) & $-0.27^{*} ; \mathrm{NS} ; \mathrm{NS}$ & & & NS; $0.28^{*} ;$ NS & & NS; $0.34^{*} ;$ NS & \\
\hline Resistin (ng/ml) & $-0.26^{*} ; \mathrm{NS} ;-0.32^{*}$ & & & & & & NS; 0.45**; NS \\
\hline TNF-a (pg/ml) & & & $0.23^{*} ; 0.34^{*} ;$ & $N S ; N S ;-0.38^{*}$ & & & $0.44^{* *} ; 0.45^{* *} ; 0.58^{* *}$ \\
\hline aPAl (ng/ml) & & NS; $0.48^{*} ; \mathrm{NS}$ & & $N S ; 0.37^{* *} ; N S$ & & $\begin{array}{c}0.44^{* *} ; 0.45^{* *} \\
0.58^{* *}\end{array}$ & \\
\hline $\mathrm{Ca}(\mathrm{mmol} / \mathrm{l})$ & & & & & & & $-0.61^{* *} ; N S ;-0.75^{* *}$ \\
\hline $\mathrm{Pi}(\mathrm{mmol} / \mathrm{l})$ & & & & & $0.36^{* *} ; \mathrm{NS} ; \mathrm{NS}$ & & \\
\hline
\end{tabular}

Note: Only significant associations were presented; Values presented as coefficient R; Coefficients presented from left to right [All, Control, Cases]; NS - Not Significant; * denotes significance at $<0.05$ level; 88 denotes significance at $<0.001$ level.

variables in all subjects, controls and cases are shown in Table 3. Data showed that CRP was positively associated with BMI $(\mathrm{r}=0.38, \mathrm{p}=0.001)$, waist $(\mathrm{r}=0.44, \mathrm{p}>0.001)$, leptin $(r=0.44, p>0.001)$ and negatively associated with adiponectin $(\mathrm{r}=-0.27, \mathrm{p}=0.02)$ and resistin $(\mathrm{r}=-0.26$, $\mathrm{p}=0.02)$. Adiponectin was negatively associated with waist $(\mathrm{r}=-0.35, \mathrm{p}=0.001)$, triglycerides $(\mathrm{r}=-0.26, \mathrm{p}=$ $0.01)$, and CRP $(\mathrm{r}=-0.27, \mathrm{p}=0.02)$ and positively associated with HDL $(r=0.23, p=0.03)$. Leptin was positively associated with BMI $(\mathrm{r}=0.32, \mathrm{p}=0.006)$, waist $(\mathrm{r}=0.23$, $\mathrm{p}=0.05)$, hips $(\mathrm{r}=0.25, \mathrm{p}=0.04)$, CRP $(\mathrm{r}=0.26, \mathrm{p}=0.04)$, and TNF- $\alpha \quad(r=0.23, p=0.05)$. TNF- $\alpha$ was positively associated with triglycerides $(\mathrm{r}=0.26, \mathrm{p}=0.01)$, leptin $(\mathrm{r}=0.23, \mathrm{p}=0.05)$, aPAI-1 $(\mathrm{r}=0.44, \mathrm{p}<001)$. aPAI- 1 was positively associated with diastolic BP $(\mathrm{r}=0.25, \mathrm{p}=$ $0.03)$, glucose $(r=0.28, p=0.01)$, and TNF- $\alpha(r=0.44$, $\mathrm{p}<0.001)$ and negatively associated with cholesterol $(\mathrm{r}=-0.28, \mathrm{p}=0.02), \quad$ LDL $(\mathrm{r}=-0.29, \mathrm{p}=0.008)$ and calcium $(r=-0.61, p<0.001)$. Resistin was positively associated with calcium $(\mathrm{r}=0.36, \mathrm{p}=0.01)$ and negatively associated with CRP $(\mathrm{r}=-0.26, \mathrm{p}=0.02)$.

\section{Discussion}

Obesity is an established risk factor for most hormonedependent cancers, including breast cancer. The pathology underlying this phenomenon may be related to the endocrine and metabolic profile of this state. In the present case-control study, our results indicate that metabolic changes among newly diagnosed breast cancer patients are consistent with a systemic stress response, possibly because of the presence and/or diagnosis of cancer activating the stress-system that, in turn, alters further the existing metabolic state to an environment conducive to tumor growth. It has been well established that stress, both acute and chronic induces a powerful cascade of immune, metabolic and inflammatory reactions [25]. On the other hand, we cannot exclude preexisting metabolic syndrome manifestations as a risk factor 
for the development of breast cancer and the two explanations are not mutually exclusive.

Our current data suggest that there is a positive association between triglycerides and ANG II levels in patients newly diagnosed with breast cancer. ANG II is a biologically active peptide of the renin-angiotensin system (RAS) involved in blood pressure regulation, tissue remodeling and angiogenesis, as well as in vascular and inflammatory pathologies. Consequently, the major functions attributed to ANG II (inflammation, angiogenesis and migration) are also related to cancer progression [26-28]. We also showed that there is a negative association of ANG II with HDL and aPAI which were in agreement with previous studies $[29,30]$. However, other studies reported a positive association between ANG II and breast cancer [31,32]. On the other hand, a very recent study involving more than 230,000 women (Swedish AMORIS Study) showed no association between HDL and breast cancer risk, while it demonstrated a weak protective association between circulating triglycerides and risk for breast cancer [33].

Obesity is increasingly associated with postmenopausal breast cancer risk [34], whereas, in premenopausal women there is an inverse relation between BMI and breast cancer risk [35,36]. We have previously demonstrated in our cross-sectional study that inflammatory biomarkers known to be elevated in breast cancer patients (IL-6 and CRP) are also increased in obese and insulin resistant pre-menopausal women [37]. The present findings, therefore, confirm that inflammatory markers, specifically CRP and TNF- $\alpha$ are elevated in newly diagnosed patients with breast cancer.

Inflammation is associated with poor prognosis and decreased survival in many cancers. As obesity per se is considered a subclinical inflammation, the increased levels of TNF- $\alpha$ and CRP in breast cancer cases in the present study are consistent with stress-induced inflammation among newly diagnosed breast cancer patients. In addition, CRP was positively correlated with BMI and inversely with adiponectin levels, in agreement with previous reports [22,23]. Thus, in obesity, the adipocytokines and in particular, adiponectin and the inflammatory mediators might exert an additive effect to positively impact breast cancer pathogenesis.

Our data showed significantly elevated mean level of serum glucose, diastolic blood pressure and reduced HDL in the breast cancer group. Previous studies reported that high fasting glucose levels were directly correlated with breast cancer both in pre-menopausal and postmenopausal women [38,39]. In addition, reduced HDL-cholesterol and increased blood pressure contributed to increased risk for breast cancer [40,41]. Furthermore, low HDL-cholesterol, hypertension, and hyperglycemia have all been associated with breast cancer $[38,40,42-44]$.
The authors acknowledge some limitations. The casecontrol cross-sectional design limits the findings to at best, suggestive. The small sample size might explain the failure to produce significant associations in parameters that were expected to associate with clinical variables. Furthermore several confounders were excluded such as family history of breast cancer and medications and as such the findings cannot be generalized. Despite these limitations, the present study is among the few to observe pathologic changes in the adipocytokine, metabolic and immune biomarkers among early diagnosed breast cancer patients. These changes may reflect an earlier risk or a stressful environment conducive to tumor growth and/or both.

\section{Conclusions}

In conclusion, inflammatory and metabolic changes are apparent among patients with early breast cancer as evidenced by the strong positive link between CRP and BMI, the positive association between ANG II and triglycerides, the negative association between HDL and adiponectin, and the strong negative association between PAI-1 and HDL. These associations, independent of age and BMI, are consistent with stress-induced changes secondary to the early breast cancer and/or the psychologic impact of the diagnosis, might enhance tumorigenic activity and lead to a poorer prognosis if left ignored.

\section{Competing interests}

The authors declare no competing interests.

\section{Authors' contributions}

MSA and NMA conceived the study. AA, HMD, AAA and SY carried out data acquisition and interpretation. AMA and MSA analyzed the data and prepared the manuscript. SS and GPC drafted the revised and final version of the manuscript. All authors provided intellectual contributions to the manuscript and has read and approved the final version.

\section{Acknowledgements}

This study was generously funded by King Abdul Aziz City for Science and Technology (KACST), (project \# AT-28-94) Riyadh, Saudi Arabia. The authors thank Mr. Benjamin Vinodson and Mr. SaimUlhaq for the statistical analyses of the data.

\section{Author details}

${ }^{1}$ Biomarkers Research Program, Biochemistry Department, College of Science, King Saud University, Riyadh 11451, Kingdom of Saudi Arabia (KSA). ${ }^{2}$ Center of Excellence in Biotechnology, King Saud University, Riyadh 11451, KSA. ${ }^{3}$ Department of Surgery, College of Medicine, King Saud University, Riyadh 11472 , KSA. ${ }^{4}$ Department of Biochemistry, National Research Centre, Cairo 12311, Egypt. ${ }^{5}$ School of Biological Sciences, Life Science Building 85,

University of Southampton, Southampton SO17 1BJ, UK. ${ }^{6}$ First Department of Pediatrics, Athens University Medical School, Athens 11527, Greece.

${ }^{7}$ Department of Biochemistry, College of Science, King Saud University, PO Box 2455, Riyadh 11451, Kingdom of Saudi Arabia.

Received: 8 September 2012 Accepted: 30 January 2013 Published: 4 February 2013 


\section{References}

1. World Health Organization: Obesity and overweight fact sheet. May 2012. http://www.who.int/mediacentre/factsheets/fs311/en/.

2. Calle EE, Rodriquez C, Walker-Thurmond K, Thun MJ: Overweight, obesity, and mortality from cancer in a prospectively studied cohort of U.S. adults. N Eng J Med 2003, 348:1625-1638.

3. Macciò A, Madeddu C, Mantovani G: Adipose tissue as target organ in the treatment of hormone dependent breast cancer: new therapeutic perspectives. Obes Rev 2009, 10:660-670.

4. Carmichael AR: Obesity and prognosis of breast cancer. Obes Rev 2006, 7:333-340.

5. Dirat B, Bochet L, Escourrou G, Valet P, Muller C: Unraveling the obesity and breast cancer links: a role for cancer-associated adipocytes? Endocr Dev 2010, 19:45-52.

6. American Cancer Society: Breast cancer facts and figures 2005-2006. Atlanta GS: American Cancer Society Inc; 2006.

7. Krebs EE, Taylor BC, Cauley JA, Stone KL, Bowman PJ, Ensrud KE: Measures of adiposity and risk of breast cancer in older post-menopausal women. J Am Geriatr Soc 2006, 54:63-69.

8. Larsson SC, Mantzoros CS, Wolk A: Diabetes mellitus and risk of breast cancer: a meta-analysis. Int J Cancer 2007, 121:856-862.

9. Gunter MJ, Hoover DR, Yu H, Wassertheil-Smoller S, Rohan TE, Manson JE, Li J, Ho GY, Xue X, Anderson GL, Kaplan RC, Harris TG, Howard BV, WylieRosett J, Burk RD, Strickler HD: Insulin, insulin-like growth factor-l, and risk of breast cancer in postmenopausal women. J Natl Cancer Inst 2009, 101:48-60.

10. Oh SW, Park CY, Lee ES, Yoon YS, Lee ES, Park SS, Kim Y, Sung NJ, Yun YH, Lee KS, Kang HS, Kwon Y, Ro J: Adipokines, insulin resistance, metabolic syndrome, and breast cancer recurrence: a cohort study. Breast Cancer Res 2011, 13:R34

11. Pisani P: Hyper-insulinaemia and cancer, meta-analyses of epidemiological studies. Arch Physiol Biochem 2008, 114:63-70.

12. Agnoli C, Berrino F, Abagnato CA, Muti P, Panico S, Crosignani P, Krogh V: Metabolic syndrome and postmenopausal breast cancer in the ORDET cohort: A nested case-control study. Nutr Metab Cardiovasc Dis 2010, 20:41-48.

13. Xue F, Michels KB: Diabetes, metabolic syndrome, and breast cancer: a review of the current evidence. Am J ClinNutr 2007, 86:5823-s835.

14. Korner A, Pazaitou-Panayiotou K, Kelesidis T, Kelesidis I, Williams CJ, Kaprara A, Bullen J, Neuwirth A, Tseleni S, Mitsiades N, Kiess W, Mantzoros CS: Total and high-molecular-weight adiponectin in breast cancer: in vitro and in vivo studies. J Clin Endocrinol Metab 2007, 92:1041-1048.

15. Fischer $\mathrm{S}$, Hanefeld M, Haffner SM: Insulin-resistant patients with type 2 diabetes mellitus have higher serum leptin levels independently of body fat mass. Acta Diabetol 2002, 39:105-110.

16. Haluzík M, Parízková J, Haluzík MM: Adiponectin and its role in the obesity-induced insulin resistance and related complications. Physiol Res 2004, 53:123-129.

17. Han C, Zhang HT, Du L: Serum levels of leptin, insulin, and lipids in relation to breast cancer in China. Endocrine 2005, 26:19-24.

18. Tworoger SS, Eliassen AH, Kelesidis T: Plasma adiponectin concentrations and risk of incident breast cancer. J Clin Endocrinol Metab 2007, 92:1510-1516.

19. Albuquerque KV, Price MR, Badley RA: Pre-treatment serum lev-els of tumour markers in metastatic breast cancer: a prospective assessment of their role in predicting response to therapy and survival. Eur J Surg Oncol 1995, 21:504-509.

20. Zhang GJ, Adachi I: Serum interleukin-6 levels correlate to tumor progression and prognosis in metastatic breast carcinoma. Anticancer Res 1999, 19:1427-1432

21. Bozcuk H, Uslu G, Samur M: Tumour necrosis factor-alpha, interleukin-6, and fasting serum insulin correlate with clini-cal outcome in metastatic breast cancer patients treated with chemotherapy. Cytokine 2004, 27:58-65.

22. Rolland YM, Perry HM 3rd, Patrick P, Banks WA, Morley JE: Leptin and adiponectin levels in middle-aged postmenopausal women: associations with lifestyle habits, hormones, and inflammatory markers-a crosssectional study. Metabolism 2006, 55:1630-1636.

23. Yuan G, Zhou L, Tang J: Serum CRP levels are equally elevated in newly diagnosed type 2 diabetes and impaired glucose tol-erance and related to adiponectin levels and insulin sensitivity. Diabetes Res Clin Pract 2006, 72:244-250
24. Il'yasova D, Colbert LH, Harris TB: Circulating levels of inflam-matory markers and cancer risk in the health aging and body composition cohort. Cancer Epidemiol Biomarkers Prev 2005, 14:2413-2418.

25. Chrousos GP: Stress and disorders of the stress system. Nat Rev Endocrinol 2009, 5:374-381.

26. Yvan-Charvet $L$, Quignard-Boulange A: Role of adipose tissue reninangiotensin system in metabolic and inflammatory diseases associated with obesity. Kidney Int 2011, 79:162-168.

27. Muniyappa R, Yavuz S: Metabolic actions of angiotensin II and insulin: a microvascular endothelial balancing act. Mol Cell Endocrinol 2012, [Epub ahead of print].

28. Rodriguez-Ferreira S, Abdelkarim M, Dillenburg-Pilla P, Luissint AC, diTommaso A, Deshayes F, Pontes CL, Molina A, Cagnard N, Letourneur F, Morel M, Reis RI, Casarini DE, Terris B, Couraud PO, Costa-Neto CM, Di Benedetto M, Nahmias C: Angiotensin II facilitates breast cancer cell migration and metastasis. PLoS One 2012, 7:e35667.

29. Jafri H, Alsheikh-Ali AA, Karas RH: Baseline and on-treatment high-density lipoprotein cholesterol and the risk of cancer in randomized controlled trials of lipid-altering therapy. J Am Coll Cardiol 2010, 55:2846-2854.

30. Kucharska-Newton AM, Rosamond WD, Mink PJ, Alberg AJ, Shahar E, Folsom AR: HDL-cholesterol and incidence of breast cancer in the ARIC cohort study. Ann Epidemiol 2008, 18:671-677.

31. Deshayes F, Nahmias C: Angiotensin II receptors: a new role in cancer? Trends Endocrinol Metabol 2005, 16:293-299.

32. George AJ, Thomas WG, Hannan RD: The renin-angiotensin system and cancer: old dog, new tricks. Nat Rev Cancer 2010, 10:745-759.

33. Melvin JC, Seth D, Holmberg L, Garmo H, Hammar N, Jungner I, Walldius G, Lambe M, Wigertz A, Van Hemelrijck M: Lipid Profiles and Risk of Breast and Ovarian Cancer in the Swedish AMORIS Study. Cancer Epidemiol Biomarkers Prev 2012, [Epub ahead of print].

34. Dalamaga M, Karmaniolas K, Papadavid E, Pelekanos N, Sotiropoulos G, Lekka A: Elevated serum visfatin/nicotinamide phosphoribosyltransferase levels are associated with risk of postmenopausal breast cancer independently from adiponectin, leptin, and anthropometric and metabolic parameters. Menopause 2011, 11:1198-1204.

35. Michels KB, Terry KL, Willett WC: Longitudinal study on the role of body size in premenopausal breast cancer. Arch Intern Med 2006, 166:2395-2402.

36. Daling JR, Malone KE, Doody DR, Johnson LG, Gralow JR, Porter PL: Relation of body mass index to tumor markers and survival among young women with invasive ductal breast carcinoma. Cancer 2001, 92:720-729.

37. Alokail MS, Al-Daghri NM, Al-Attas O, Hussain T: Combined effects of obesity and type 2 diabetes contribute to increased breast cancer risk among premenopausal women. Cardiovasc Diabetol 2009, 8:33.

38. Muti P, Quattrin T, Grant BJ: Fasting glucose is a risk factor for breast cancer: a prospective study. Cancer Epidemiol Biomarkers Prev 2002. 11:1361-1368.

39. Rapp K, Schroeder J, Klenk J: Fasting blood glucose and cancer risk in a cohort of more than 140,000 adults in Austria. Diabetologia 2006, 49:945-952.

40. Furberg AS, Veierød MB, Wilsgaard T, Bernstein L, Thune I: Serum highdensity lipoprotein cholesterol, metabolic profile, and breast cancer risk. J Natl Cancer Inst 2004, 96:1152-1160.

41. Soler M, Chatenoud L, Negri E, Parazzini F, Franceschi S, la Vecchia C: Hypertension and hormone-related neoplasms in women. Hypertension 1999, 34:320-325.

42. Peeters $\mathrm{PH}$, van Noord PA, Hoes AW, Fracheboud J, Gimbrère CH, Grobbee DE: Hypertension and breast cancer risk in a 19-year follow-up study (the DOM cohort). Diagnostic investigation into mammarian cancer. J Hypertens 2000, 18:249-254.

43. Pichard C, Plu-Bureau G, Neves-eCastro M, Gompel A: Insulin resist-ance, obesity and breast cancer risk. Maturitas 2008, 60:19-30.

44. Chong YM, Williams SL, Elkak A, Sharma AK, Mokbel K: Insulin-like growth factor 1 (IGF-1) and its receptor mRNA levels in breast cancer and adjacent non-neoplastic tissue. Anticancer Res 2006, 26:167-173.

doi:10.1186/1471-2407-13-54

Cite this article as: Alokail et al: Metabolic syndrome biomarkers and early breast cancer in Saudi women: evidence for the presence of a systemic stress response and/or a pre-existing metabolic syndromerelated neoplasia risk?. BMC Cancer 2013 13:54. 